\title{
A Usability Model for Government Web Sites
}

\author{
Deborah S. Carstens and Annie Becker \\ Florida Institute of Technology \\ $150 \mathrm{~W}$. University Blvd. \\ Melbourne, Florida 32901, USA \\ \{carstens, abecker\}@fit.edu
}

\begin{abstract}
A usability model is proposed for developers of government Web sites. The model is based on the findings of a study to identify potential usability barriers of state government Web sites when accessing information on government accountability. The model was then applied during a heuristic evaluation of fifty government Web sites. The model is based on four core usability components consisting of readability, reading complexity, navigation and supportability. The model is discussed in terms of its practical application for improving state government Web sites for the purposes of enhancing the usefulness and ease of use in navigating state government Web sites.
\end{abstract}

Keywords: Usability, Government Accountability, Government Web sites.

\section{Introduction}

A usability model is proposed for developers of government Web sites. The model is based on the findings of a study to identify potential usability barriers of state government Web sites when accessing information on government accountability. Application of the model took place during a heuristic evaluation of fifty government Web sites. The model is based on four core usability components consisting of readability, reading complexity, navigation and supportability. The reading component is comprised of font size, font type, resizing capabilities and screen reader compatibility. The reading complexity component is based on the Flesch Reading Ease score. The navigation component considers the use of breadcrumb trails, links leading to external sites, table of contents and images without labels used to navigate as well as the amount of clicks necessary to access information. The supportability component takes into consideration the amount of support information displayed on a Web site such as contact information, live online help, privacy policy and accessibility policy as well as whether feedback from a user of a Web site can be submitted.

The model is discussed in terms of its practical application for improving state government Web sites for the purposes of enhancing the usefulness and ease of use in 
navigating state government Web sites. Web developers of State government sites may find these results insightful in promoting site usability for all citizens of all ages.

\section{Web Site Usability}

Application of Human Computer Interaction (HCI) in technology results in usability, universality, and usefulness [9]. Bainbridge [3: 4] defines usability as, "a user interface is the aspect of a Web site (or application) that the user interacts with and experiences first-hand." Usability is a quantitative and qualitative measurement of the design of a user interface, grouped into five key factors: learnability, efficiency, memorability, errors, and satisfaction." These five factors are based on Nielson's [9] five attributes associated with usability. Learnability refers to the ease of use in learning the system. Efficiency looks at how productive the system user can be once having learned the software. Memorability refers to the user being able to recall how to use the system even after a certain period of time has elapsed. Satisfaction is attributed to how pleasant the Web site or system is to use taking into account user frustration associated with using a site.

Web usability research has extended to include Web designs that are usable by older adults and those with vision deficiencies or impairments [4\&5]. Web designs that do not take into account vision, for example, may pose barriers to a large user group. According to the American Foundation for the Blind [1\&2], approximately 6.2 million older adults (65 and over) have vision loss and approximately 9 million Americans, 45 to 64, have vision loss. Furthermore, 1in 12 males or $8 \%$ of the male population is colorblind, 10 million individuals wear glasses and are still visually impaired and over 1 million individuals are legally blind.

The study, described in this paper, builds upon recent studies conducted by Becker, Carstens and Linton [6] and Carstens and Becker [7]. The study customized heuristics to take into account both user profiles (e.g., vision associated with normal aging) and the objective of using the Web site (e.g., informational links provided on a homepage). This customization is done to gather meaningful data about Web usability associated with a particular site. Bainbridge [3] and Carstens, Feizi and Malone [8], for example, tested Web sites for travel sales using specific heuristics related to online accommodations. Becker assessed the usability of health-related Web sites by older adults in search of health resources [5].

\section{Methodology}

A usability model for developers of government Web sites was developed and tested. The methodology utilized is listed below:

Step 1: The model was first developed based on the findings of a study to identify potential usability barriers of state government Web sites when accessing information on government accountability. This specific study that resulted in the development of the model followed the steps below: 
Step 1.1: Identification of state government Web sites with cost and performance data made accessible to the public. The Web sites selected in this study included FloridaPerforms.com, VirginiaPerforms.com, and the State of Washington Transportation Improvement Board GMAP Performance Management Dashboard.

Step 1.2: Development of usability criteria to measure and assess each of the three government Web sites in terms of potential usability barriers. The criteria used to assess each Web site was focused on usability by citizens from all adult age groups. The criteria consisted of: text resizing capabilities, screen reader compatibility, readability, navigation, understandability, consistency, reading complexity, errors, number of years of data, cited source information and availability of help information.

Step 1.3: Evaluation of each state government Web site utilizing the usability criteria. The screen reader tool, WebAnywhere, was used in the evaluation of each site to take into account usability from the perspective of vision impairment or blindness. WebAnywhere is a web-based screen reader developed at the University of Washington with funding support by the National Science Foundation. The tool enables blind people to access the web from any computer with a sound card. For more information, visit http://webanywhere.cs.washington.edu/.

Step 1.4: Identification of potential usability barriers that include older adult users and those with vision impairments.

Step 1.5: Identification of model guidelines for developers of government Web sites to use in pursuit of universal usability by all constituents.

Step 2: The model was then applied during a heuristic evaluation of fifty government Web sites. This specific study that resulted in the development of the model followed the steps below:

Step 2.1: Identification of the fifty state Web sites.

Step 2.2: Test the model that was developed from the first study findings by evaluating each state Web site utilizing the usability criteria in the model.

Step 2.3: Identification potential usability barriers of the fifty Web sites that include elder adult users and those with vision impairments.

Step 2.4: Identification of the practical application of the research study in providing usability guidelines to developers of Web sites based on the heuristic evaluation performed.

Step 3: Identification of the final version of the model that provides usability guidelines to developers of government Web sites.

\section{Results}

The research findings are in the form of a proposed usability model which consists of guidelines for developers of government Web sites to utilize. The model was developed and applied in studies and is displayed in Fig. 1. 


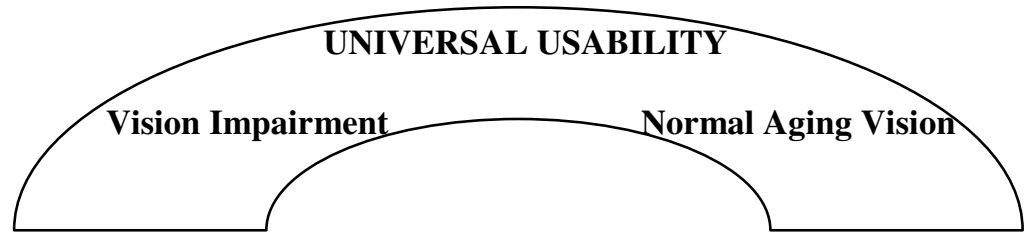

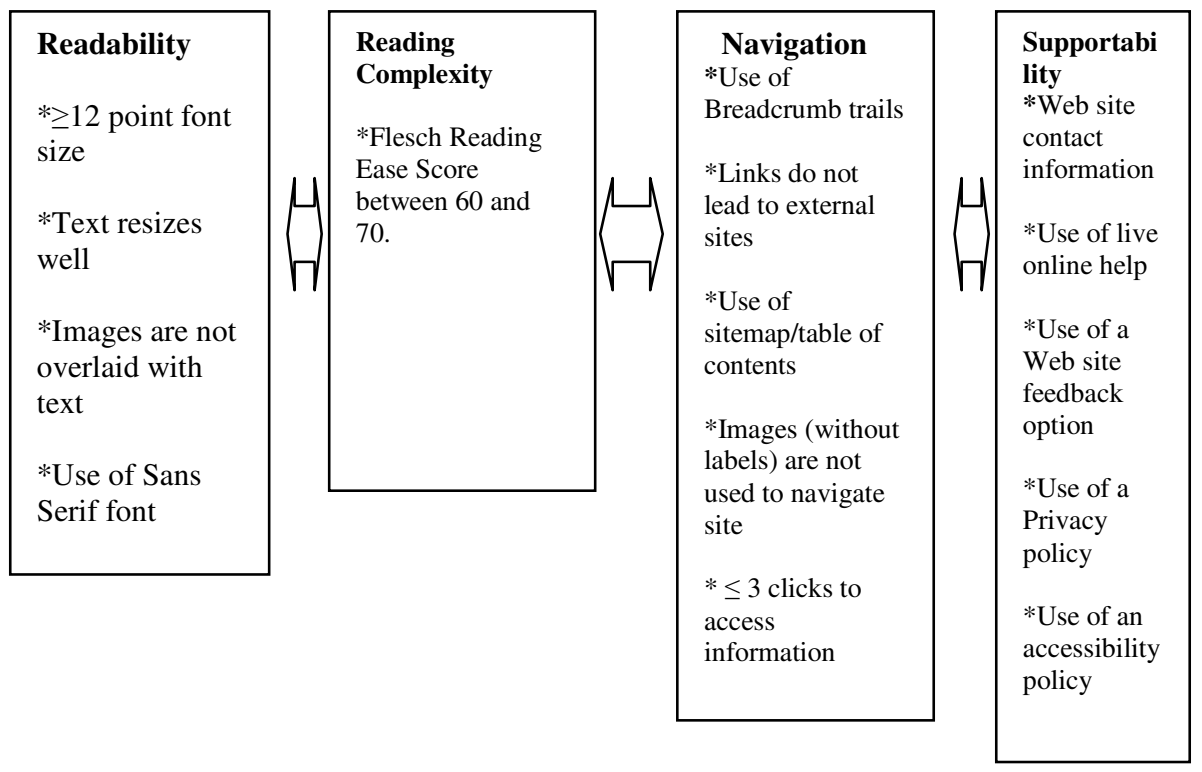

Fig. 1. Usability Web Site Model to Promote Universal Usability

\section{Conclusion}

The usability Web site model to promote universal usability is based on four components each of which are discussed in this section.

Readability. There are design components that may adversely impact readability. These components consist of: (1) Text format on sites being 12 point font size or smaller is difficult to read; (2) Resizing text option should enable the text size to be increased without distorting the web site graphics and text; (3) Images that have text overlay make the reading of text difficult; (4) Text exceeding three pages in length are better served by providing multiple pages of information versus one very long page of text; and (5) Use of non-sans serif text format is difficult to read.

Reading Complexity. The Flesch Reading Ease readability score formula rates text on a 100-point scale based on the average number of syllables per word and words per sentence. The higher the Flesch Reading Ease score, the easier it is to understand the 
document. For most standard documents, aim for a Flesch Reading Ease score of approximately 60, standard score, to 70, fairly easy. For more information on Flesch Reading Ease score, visit http://rfptemplates.technologyevaluation.com/ReadabilityScores/Flesch-Reading-Ease-Readability-Score.html.

Navigation. There are several design components to consider in determining if a Web site is intuitive for a user. Design components that adversely impact the use of the Web site: (1) Breadcrumb trails are not used to provide navigational support; (2) External links or menu options transfer a user to an external link where the user is directed outside of the initial site without notification about leaving the initial egovernment site; (3) Table of Contents do not exist to assist the user in navigating throughout a site; (4) Images without any form of labeling (labeling is needed for a screen reader tool) are used to provide navigation to users and (5) Users have to click through more than three links to access desired information.

Supportability. There are several design components that may impact supportability for a user: (1) Lack of contact information available on the Web site; (2) Web site does not have live online help such as online chat options; (3) Web site does not have feedback options for users to provide comments for improvement of a web site; (4) Site has no privacy policy listed which is a legal document that discloses some or all of the ways a party gathers, uses, discloses and manages a user's data; and (5) Site has no accessibility policy identifying how users with disabilities can access the web site thereby ensuring equal access to electronic and information technologies.

\section{References}

1. American Foundation for the Blind. Normal changes in the aging eye (2004), http: / /www . afb.org/Section. asp? SectionID=35\&TopicID= $212 \&$ SubTopicID=39 (retrieved April 26, 2009)

2. American Foundation for the Blind. Normal changes in the aging eye (2009), http: / / www . afb.org/Section. asp? SectionID=35\&TopicID= $212 \&$ SubTopicID=39 (retrieved March 10, 2011)

3. Bainbridge, A.: Hotel booking process: Design \& usability (1.02) (February 2003), http: / / www. tourcms.com/company/research/pdf/hotel_booking_pro cess_february2003.paf (retrieved March 11, 2011)

4. Becker, S.A.: E-government Visual Accessibility for Older Adult Users. Social Science Computer Review 22(1), 11-23 (2004)

5. Becker, S.A.: A Study of Web Usability for Older Adults Seeking Online Health Resources. ACM Transactions on Human-Computer Interaction 11(4), 387-406 (2004)

6. Becker, S.A., Carstens, D.S., Linton, T.M.: Heuristic Evaluation of State Electronic Government to Promote Usability for Citizens of All Age. Journal of Management \& Engineering Integration (2010)

7. Carstens, D.S., Becker, S.A.: A Heuristic Study on the Usability of State Government Performance Data Web Sites. Issues in Innovation 4(1), 15-44 (2009)

8. Carstens, D.S., Feizi, S., Malone, L.: Traveling Abroad? A Usability Assessment of Travel Sales Web sites. Journal of Management \& Engineering Integration 2(1), 17-24 (2009)

9. Nielson, J.: Usability Engineering. Morgan Kaufmann, San Diego (1993) 